Moreno arquitectos

Maipú, Chile

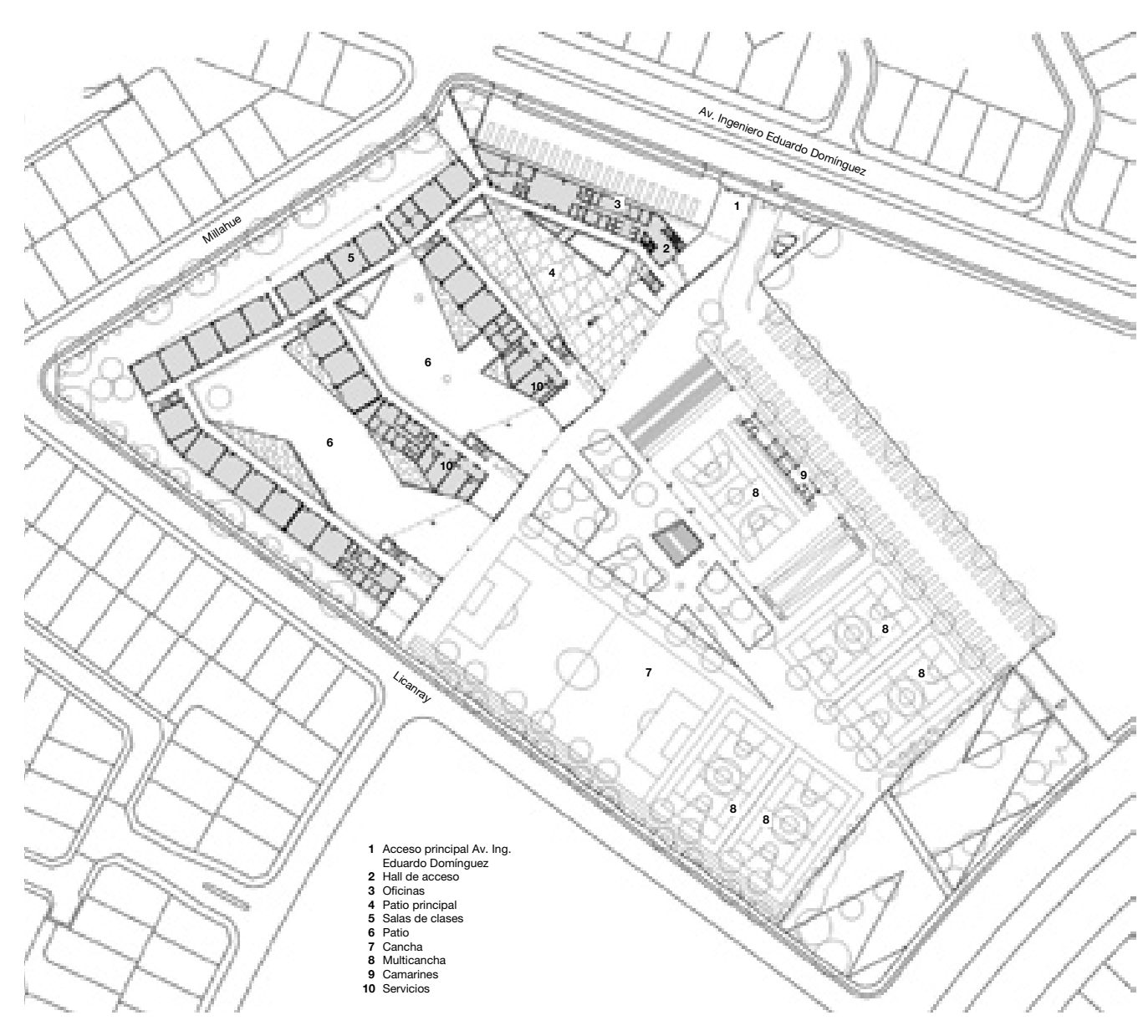

Planta emplazamiento, proyecto completo

\title{
Colegio Alicante del Rosal
}

Ubicado en el límite de Maipú, el colegio Alicante del Rosal responde a la necesidad urbana de ir consolidando la infraestructura de equipamiento en función de la demanda comercial que generan sus habitantes.

En medio de un paisaje todavía semi-rural en constante transformación, con una presencia extensiva de viviendas (de carácter anodino y repetitivo) el encargo consideraba posicionar al colegio como un referente urbano de calidad que recuperara la imagen de la edificación pública, hoy asumida por el binomio educacional particular-subvencionado en el marco de la reforma educacional chilena.

El volumen de tres pisos y fachada continua hacia el exterior, reinterpreta la idea del monasterio al organizarse espacialmente en torno a tres patios en forma de claustros que dividen los ciclos de educación en básica inferior, superior y media. Estos patios se abren hacia el sur atravesando el principal eje de circulación o pasillo cubierto (oriente-poniente) para relacionarse con el área de uso deportivo exclusivo y enmarcar las vistas lejanas hacia el campanario del Templo Votivo de Maipú. De modo inverso, esta fachada aporticada de silueta irregular y escala monumental, apreciable desde la Autopista del Sol, intenta mantener un diálogo permanente con su referencia geográfica más importante, la Cordillera de la Costa.

\section{La arquitectura como operación o la deformación de la caja}

Nos interesa el proyecto de arquitectura como una operación formal, es decir, un conjunto de reglas (principios y mecanismos) que permiten, partiendo de una o varias cantidades o expresiones, llamadas datos (programa), obtener otras cantidades o expresiones llamadas resultodos (proyecto).

Reglas
[principio (deformación) $+\underset{x}{\mathrm{x}}$ mecanismos (cortes y pliegues)]
datos (programa) $=$
resultado (proyecto)


1 Acceso desde Av. Ingeniero Eduardo Domínguez.

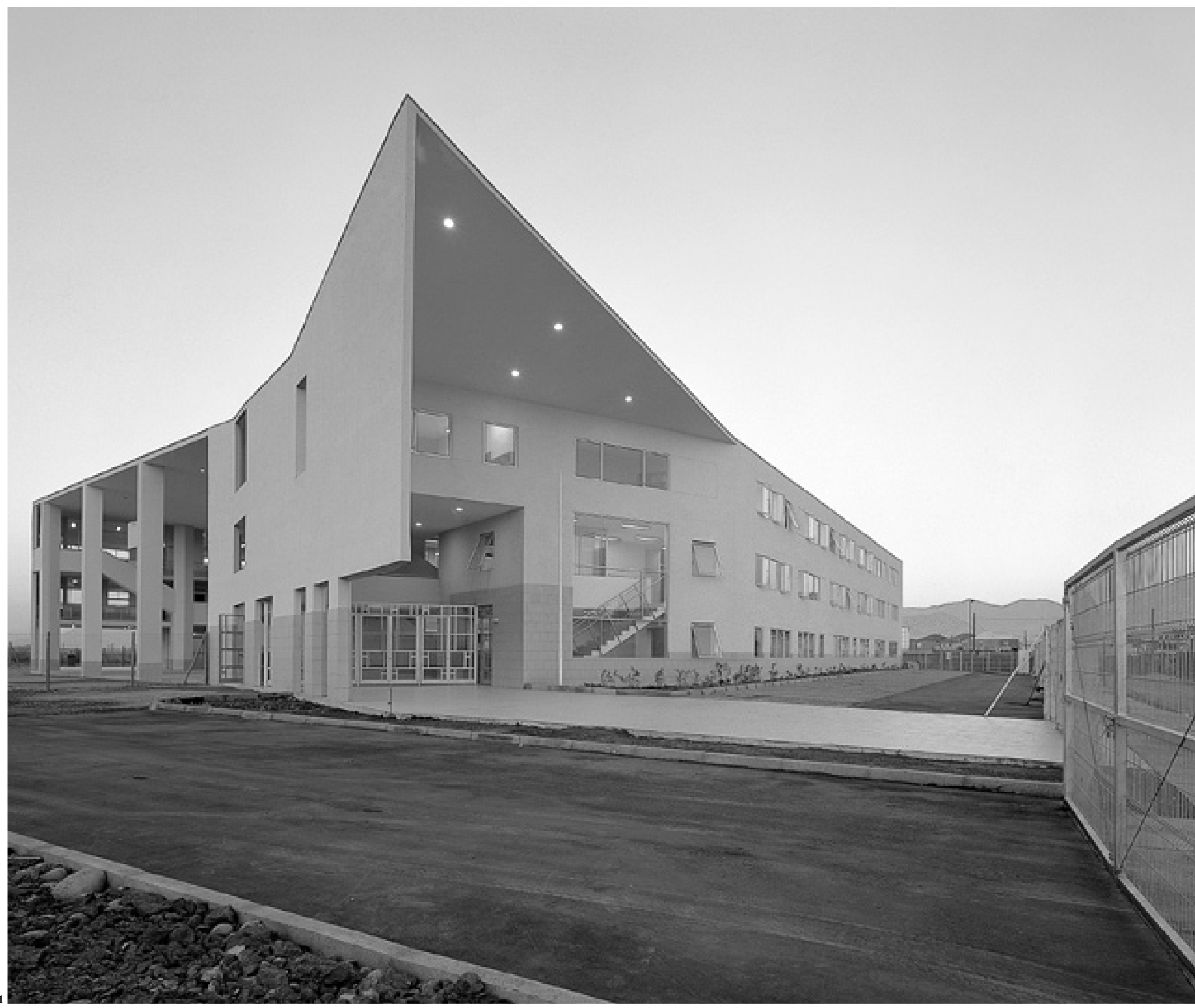



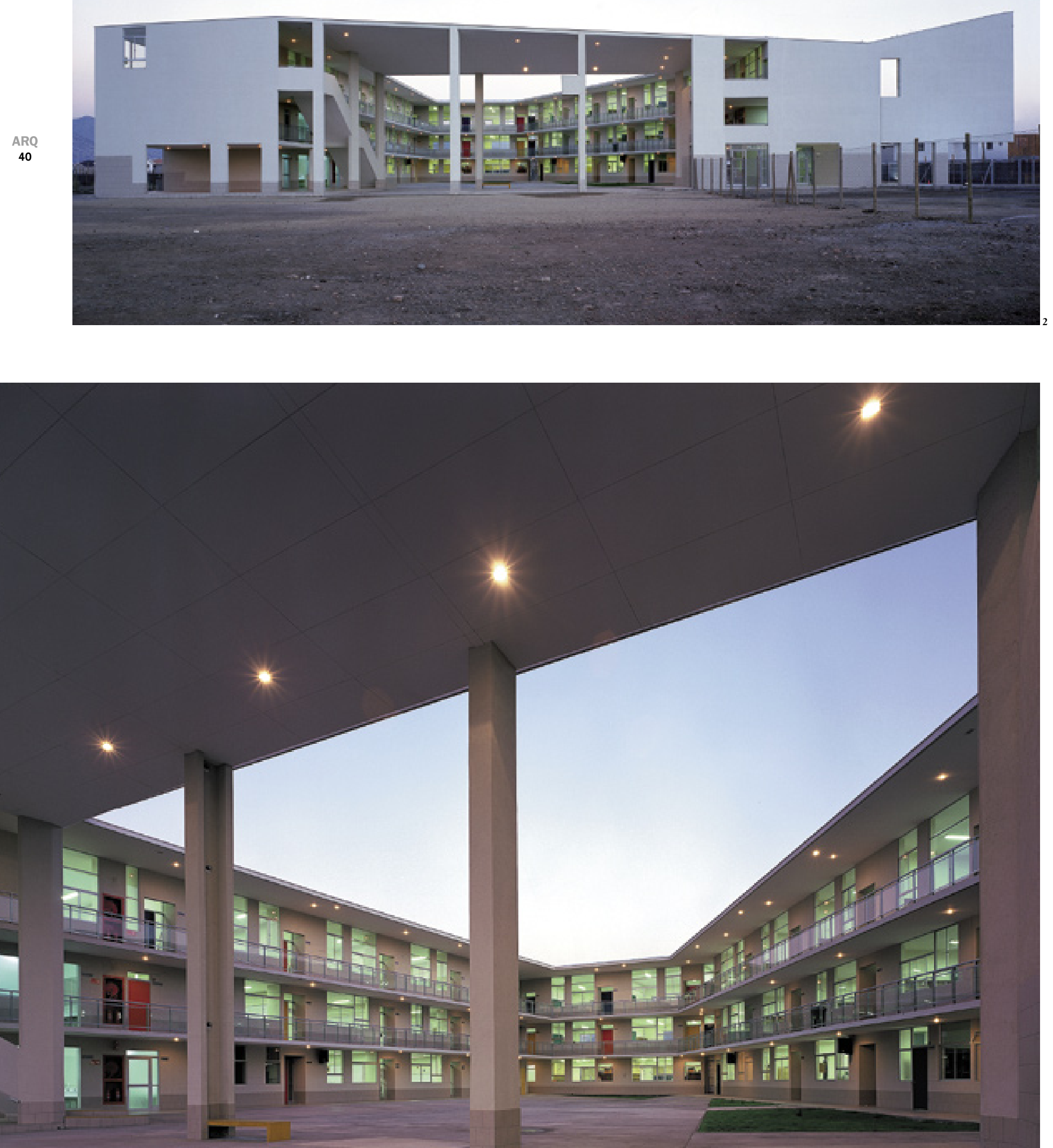

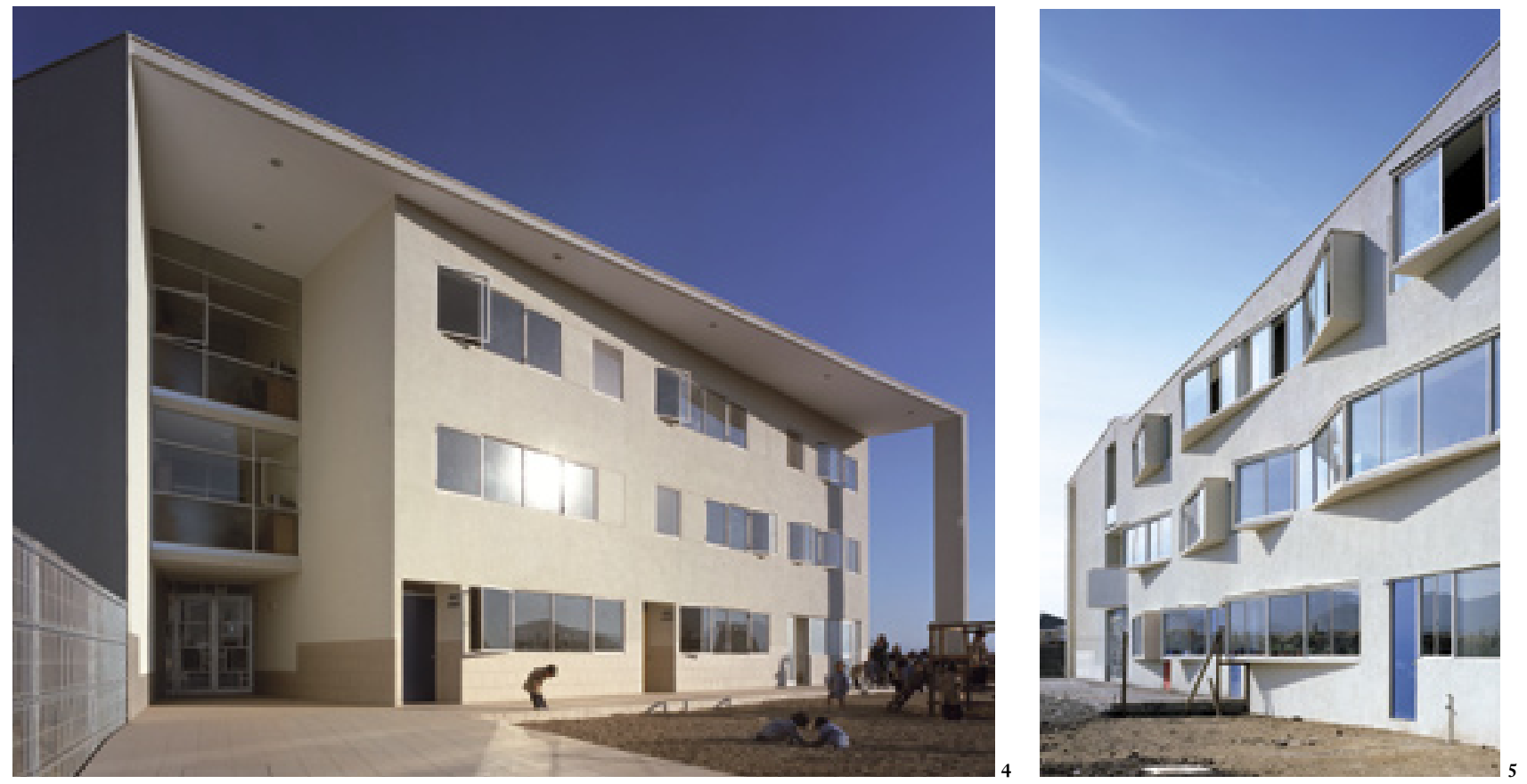

2 Vista del patio central desde el área de futuras canchas 3 Gran marquesina entre patio y canchas, eje cubierto riente-poniente

4 Fachada norte, pabellón

primera etapa hacia calle Millahue

5 Fachada poniente, pabellón primera etapa

6 Vista hacia área de canchas

desde patio central y

marquesina
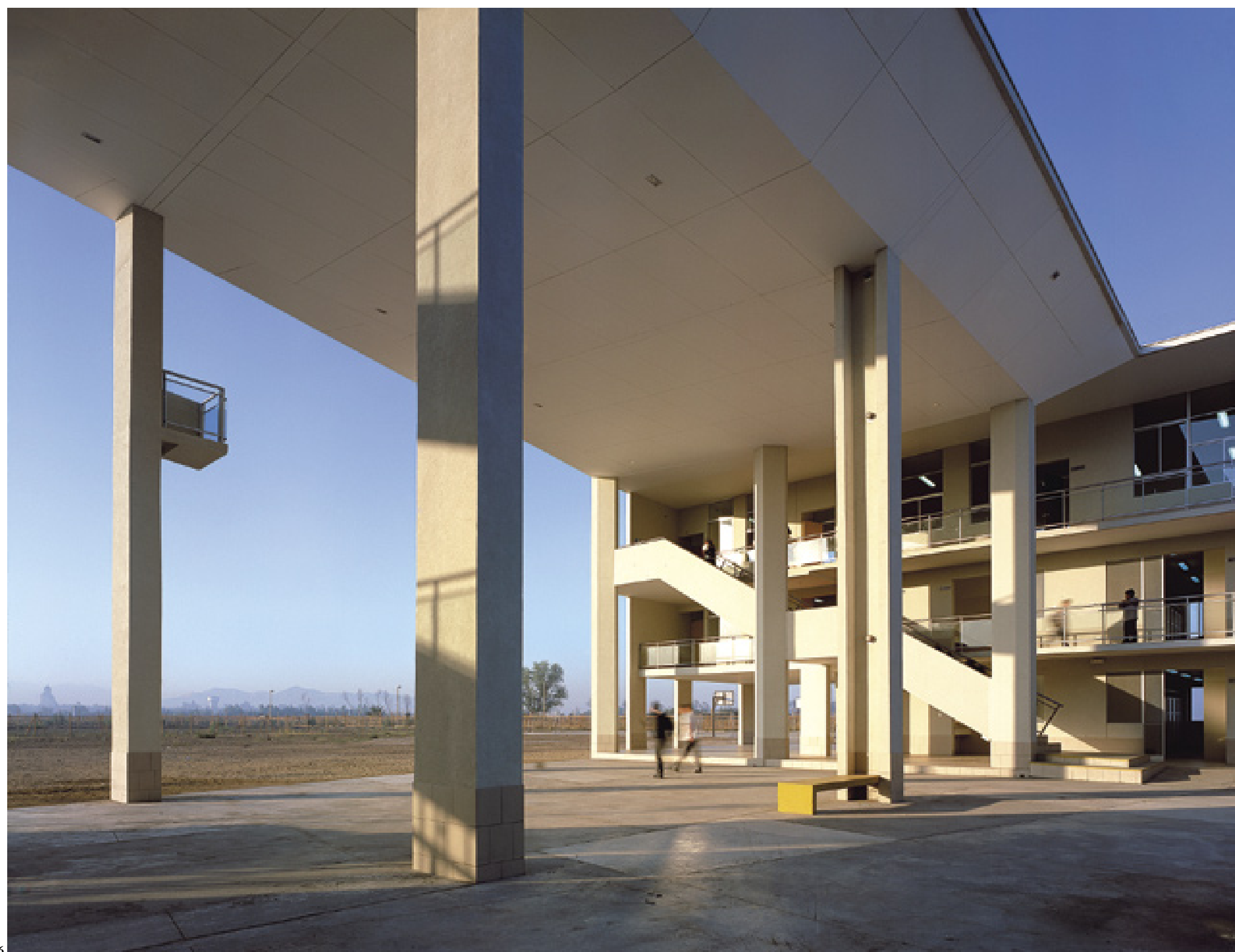


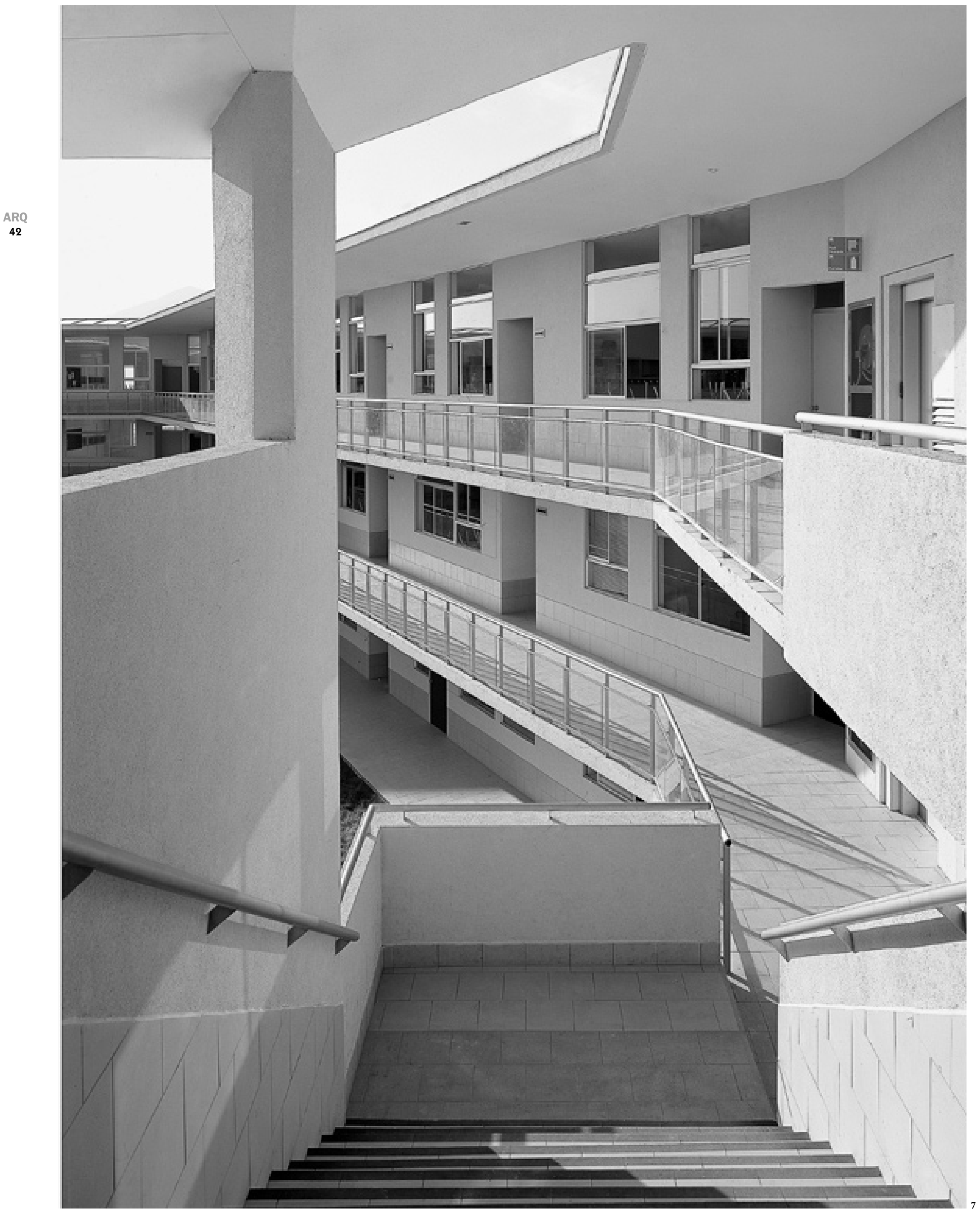




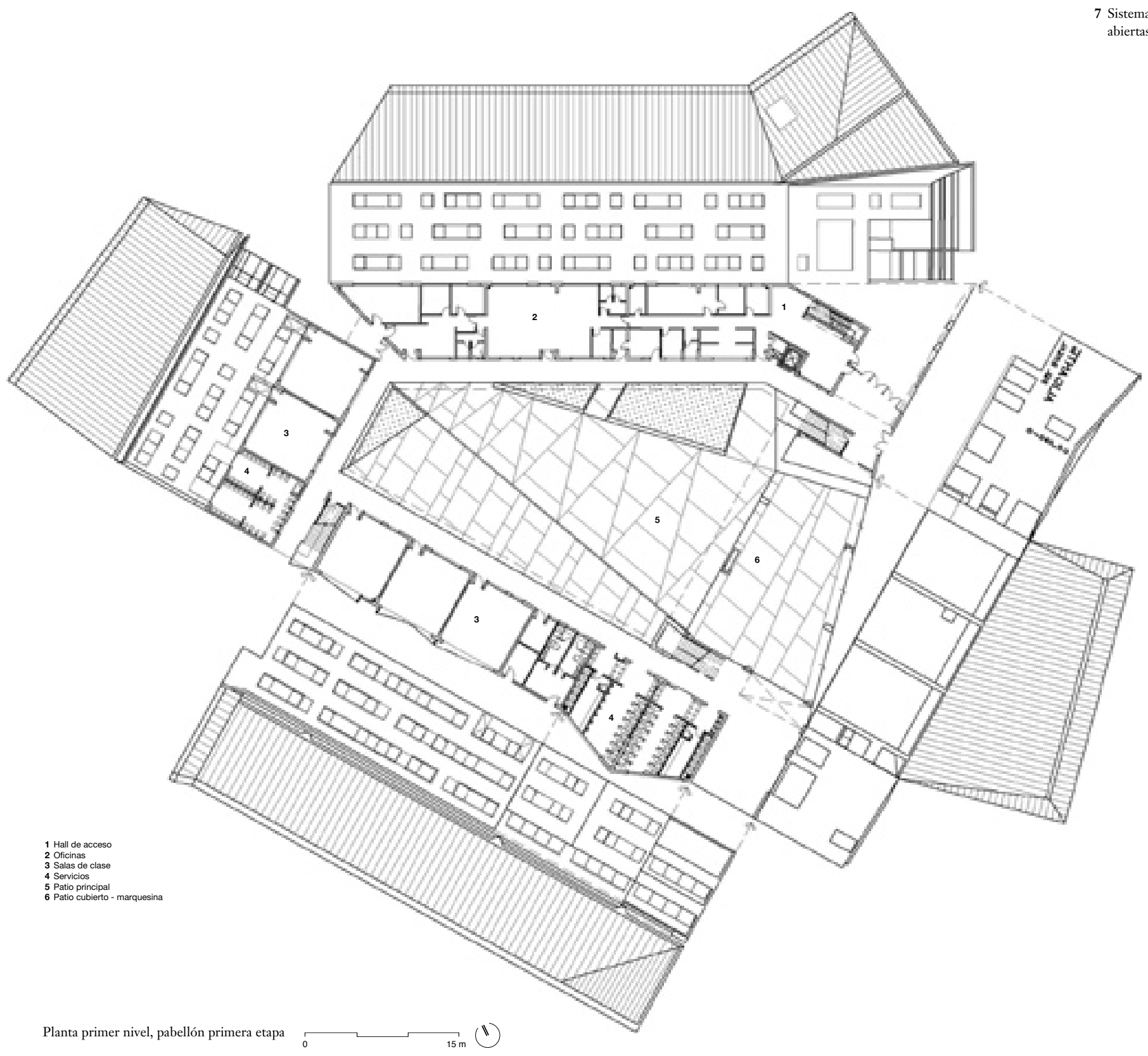

Sistema de circulaciones abiertas al patio central

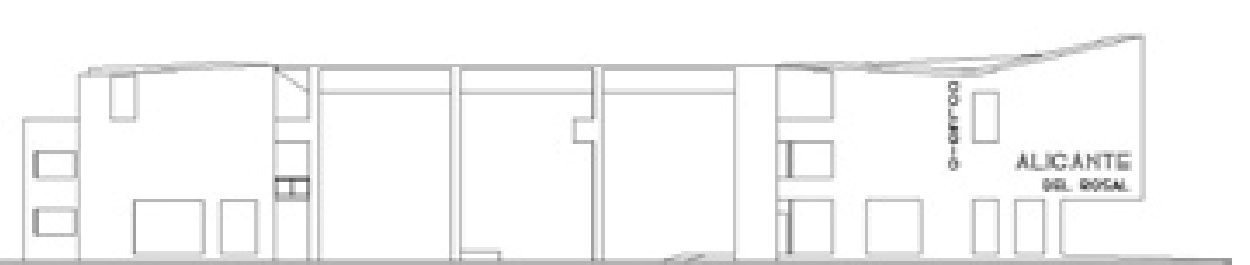

Elevación sur, portal hacia campo de deportes

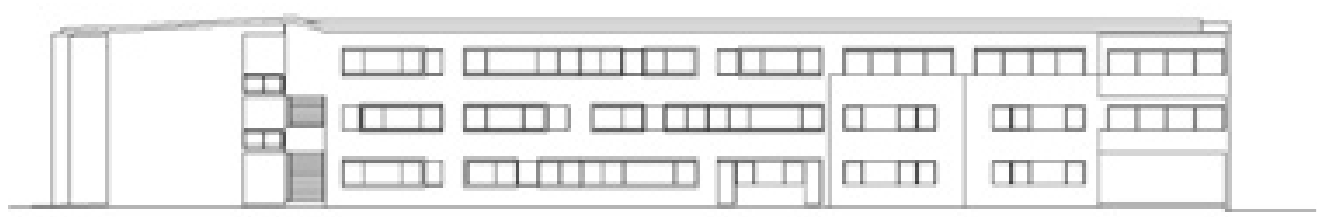

Elevación poniente

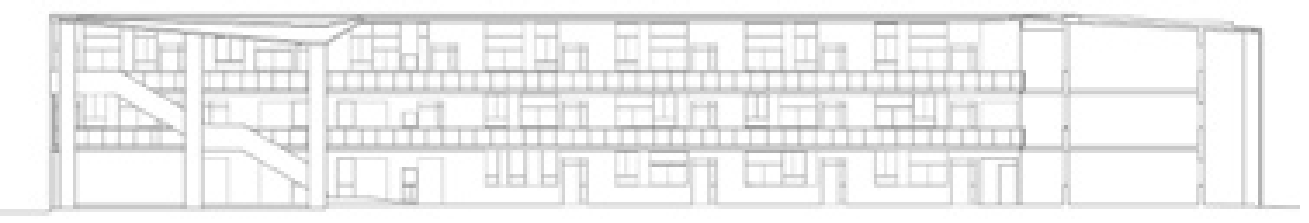

Corte longitudinal, patio interior

\section{Colegio Alicante del Rosal}

Arquitectos Moreno Arquitectos Ltda. Jorge Marsino y Cristián Contreras (coordinador de proyecto) Colaboradores Rodrigo Toro, Claudio Santandery Jaime Fuentes Ubicación Av. Ing. Eduardo Domínguez 920, La Farfana, Maipú, Chile

Cliente Soc. Educacional Alicante del Rosal Cálculo estructural Cavalla, Raby, López Construcción Ingetasco S.A.

Inspección técnica Sergio Labra Instalaciones sanitarias Manuel Catrihual Proyecto eléctrico Mauricio Campos Mecánica de suelos Petrus Ingenieros Ltda. Materialidad Muros de hormicón estucados, pavimentos exteriores de hormigón afinado, pavimentos interiores en porcelanato, carpintería metálica de aluminio Presupuesto de la obra 12,5 UF/ m² (US\$304/ m²) Superficie terreno $10.017 \mathrm{~m}^{2}$ (colegio) $+10.000 \mathrm{~m}^{2}$ (área deportiva) Superficie construida: $3.500 \mathrm{~m}^{2}$ - primera etapa, 3.600 alumnos $\times 3 \mathrm{~m}^{2} /$ alumno $=10.500 \mathrm{~m}^{2}$ de proyecto completo Año proyecto 2002

Año construcción 2003

Fotografía Guy Wenborne 